\title{
PEMBUATAN TURBIN VORTEX DENGAN SUDU PIPA BELAH TIGA DENGAN SUDUT KEMIRINGAN SUDU $45^{\circ}$
}

\author{
Gatot Suwoto, Supriyo \\ Jurusan Teknik Mesin, Politeknik Negeri Semarang \\ Email: gatot.suwoto@polines.ac.id
}

\begin{abstract}
Abstrak
Tujuan dari program ini adalah mengembangkan, merekayasa, dan membandingkan turbin air vortex dengan sudu yang berbentuk pipa belah tiga dengan sudut sudu $0^{\circ}$ dan sudut kemiringan sudu $45^{\circ}$. Metode yang digunakan yaitu tahapan perancangan turbin, proses pengerjaan, prosedur pengujian, langkah - langkah pengujian. Variabel penelitian adalah sudut kemiringan sudu dan parameter uji yang diukur adalah head aliran, debit aliran, putaran turbin, dan beda tekanan. Data yang didapat dari pengujian turbin dibuat grafik karakteristik kinerja turbin, kemudian dianalisa dan dibuat optimalisasinya. Tahap akhir dari penelitian ini adalah mendapatkan hasil kinerja turbin dan selanjutnya dibuat artikel ilmiah yang berguna bagi masyarakat umum. Hasil pengujian didapatkan pada bentuk sudu pipa belah tiga dengan sudut sudu $0^{\circ}$ pada putaran turbin 65,7 rpm yang menghasilkan efisiensi tertinggi sebesar 9,094\%, sedangkan pada sudut kemiringan sudu $45^{\circ}$ pada putaran turbin 75,8 rpm yang menghasilkan efisiensi tertinggi sebesar $11,755 \%$. Dari perbandingan bentuk sudu pipa belah tiga dengan sudut sudu $0^{\circ}$ dan sudut kemiringan sudu $45^{\circ}$ disimpulkan bahwa sudut kemiringan sudu $45^{\circ}$ memiliki efisiensi yang lebih baik.
\end{abstract}

Kata Kunci : Turbin Air Vortex, Sudu Pipa Belah Tiga, Efisiensi

\section{PENDAHULUAN}

Energi pada saat sekarang ini semakin berkurang akibat penggunaan energi fosil secara berlebihan disemua bidang, ilmuwan diseluruh dunia menyadari hal ini dan mencoba berbagai energi alternatif. Salah satu sumber energi yang banyak dilakukan penelitian adalah arus air. Penggunaan berbagai macam turbin semakin maju. Indonesia adalah negara agraris dengan potensi sumber daya air terbesar ke 5 didunia. Potensi sumber daya air yang sangat melimpah dengan jumlah total sekitar 3.200 miliar $\mathrm{m}^{3} /$ tahun (Kirmanto, Djoko.2012). Sehingga turbin air lebih diutamakan dari pada turbin angin karena angin di Indonesia relatif kurang stabil.

Pembangkit listrik tenaga air saat ini menjadi salah satu pilihan dalam memanfaatkan sumber energi terbaru, namun pemanfaatan yang ada masih menggunakan teknologi yang sederhana. Pembangkit listrik jenis ini dalam proses pembuatannya sangat ekonomis, tetapi masih dalam skala kecil. Artinya pembangkit-pembangkit seperti ini hanya mampu mencukupi pemakaian energi listrik untuk sejumlah rumah saja. Jenis pembangkit listrik tenaga air ini sering disebut microhydro atau sering juga disebut picohydro tergantung keluaran daya listrik yang dihasilkan. Teknologi ini terdiri dari komponen utama yaitu turbin air dan generator listrik (Marsudi, Djiteng. 2005). Turbin air berperan untuk mengubah energi air (energi potensial, tekanan dan energi kinetik) menjadi energi mekanik dalam bentuk putaran poros. Putaran poros turbin ini akan diubah oleh generator menjadi tenaga listrik. Microhydro ataupun picohydro yang dibuat biasanya memanfaatkan air terjun dengan head jatuh yang besar. Sedangkan untuk aliran sungai dengan head jatuh yang kecil belum termanfaatkan dengan optimal. Padahal di Indonesia terdapat potensi air sungai yang berasal dari 5.590 aliran sungai yang tersebar diberbagai pulau di Indonesia. Hal ini menjadi referensi untuk memanfaatkan 
dengan mengubahnya menjadi aliran vortex (pusaran air).

Turbin Vortex adalah salah satu jenis turbin microhydro yang menggunakan pusaran air sebagai penggerak sudunya. Turbin Vortex bekerja pada head yang rendah $0,7 \mathrm{~m}-3 \mathrm{~m}$ dengan debit $50 \mathrm{~L} / \mathrm{s}$ (Mohanan,Anjali M. 2016). Turbin jenis ini sangat cocok digunakan untuk aliran sungai, karena kebanyakan sungai memiliki head yang rendah. Berdasarkan uraian diatas, telah dikembangkan turbin vortex dengan sudu pipa belah tiga dengan sudut sudu $0^{\circ}$. Dalam penelitian ini akan dilakukan pengembangan turbin air Vortex dengan bentuk sudu pipa belah tiga dengan sudut kemiringan sudu $45^{\circ}$ dengan tujuan untuk meningkatkan efisiensi.

\section{Perumusan Masalah}

Perumusan masalah dalam penelitian ini adalah apakah bentuk saluran air yang kami rekayasa menjadi vortex dan bentuk sudu yang dimodifikasi dengan bentuk sudu pipa belah tiga dengan sudut kemiringan sudu $45^{\circ}$ dapat meningkatkan efisiensi,untuk menjawab pertanyaan tersebut, dalam penelitian ini akan dibuat 2 model turbin air tipe turbin vortex dengan sudu berbentuk pipa belah tiga dengan sudut kemiringan sudu $45^{\circ}$ dan tipe turbin vortex dengan sudu berbentuk pipa belah tiga dengan sudut sudu $0^{\circ}$. Kedua model tersebut di uji kinerjanya dan dibandingkan berdasarkan karakteristik efisiensi yang dihasilkan.

\section{METODE PENELITIAN}

Dalam program penelitian ini metode yang digunakan adalah dengan melakukan penelusuran sumber-sumber pustaka yang terkait dengan penelitian kami, serta dengan cara melakukan pengujian terhadap turbin yang kami buat. Untuk mendapatkan pemahaman yang komprehensif, langkahlangkah penelitian diuraikan seperti berikut ini. Persiapan langkah ini dilakukan berdasarkan objek penelitian meliputi jurnaljurnal dan artikel. Metode ini dilakukan dengan cara menelusuri di internet dan mempelajari buku-buku tentang turbin angin yang telah ada dari perpustakaan. Desain model turbin,setelah melakukan studi pustaka didapatkan beberapa sumber pustaka tentang model turbin

Pada turbin vortex kali ini, komponen yang dirancang meliputi sudu turbin dan poros universal sudu turbin untuk mengatur sudut kemiringan sudu. Sudu turbin terbuat dari lembaran plat stainless steel dengan tebal 0,5 $\mathrm{mm}$ yang kemudian dibentuk pipa belah tiga yang sudut kemiringannya dibuat sudut $45^{\circ}$ dan pipa belah tiga sudut $0^{\circ}$ sebagai pembanding. Turbin Vortex yang kami buat memiliki empat buah sudu terbuat dari lembaran plat stainless steel dengan tebal $0.5 \mathrm{~mm}$ dengan ukuran $60 \mathrm{~cm} \times 30 \mathrm{~cm}$.

Teknik pengumpulan data didapatkan dengan menggunakan alat uji turbin votex, untuk memutar turbin air vortex, tachometer untuk mengukur putaran turbin, manometer $\mathrm{U}$ untuk mengukur beda ketinggian, mengukur tegangan dengan menggunakan voltmeter dan arus dengan menggunakan amperemeter. Uji kinerja turbin,dilakukan dengan menggunakan sudut kemiringan sudu dengan variasi puntiran sudut $0^{\circ}$ dan sudut $45^{\circ}$. Parameter yang diukur dalam pengujian ini yaitu putaran turbin, beda ketinggian pada manometer $\mathrm{U}$, tegangan dan arus.

Setelah semua pengujian selesai maka didapat data hasil kinerja dari turbin dan selanjutnya dapat dibuat grafik karakteristik kinerja dari turbin tersebut. Melakukan pengolahan data dan ditunjukan dalam bentuk tabel dan kurva karakteristik kinerja turbin vortex.

3. HASIL DAN PEMBAHASAN Alat uji turbin vortex yang kami gunakan dalam penelitian ini adalah seperti gambar di bawah ini 
Berikut adalah keterangan:

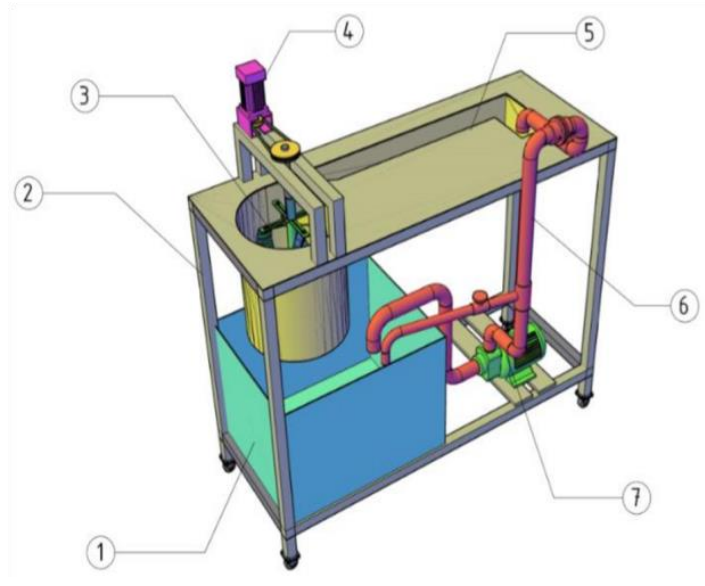

Gambar 1. Seperangkat Alat Uji Turbin Vortex dari seperangkat alat uji Turbin Vortex :

1. Bak penampung air

2. Rangka

3. Turbin

4. Generator

5. Saluran Air

6. Pipa

7.
Tabel 1. Data hasil perhitungan sudu pipa belah 3 dengan sudut sudu $0^{\circ}$

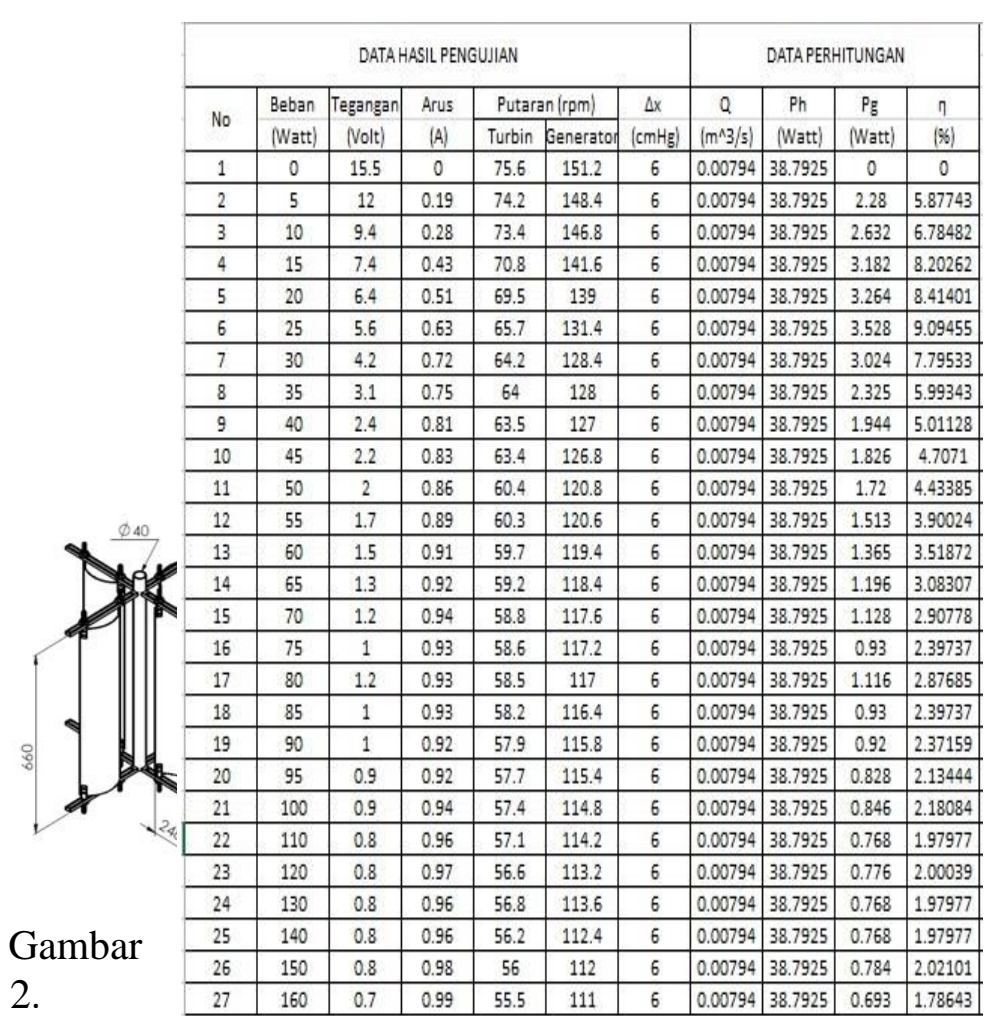

Kompo

nen Turbin Vortex Sudut

Sudu $0^{0}$
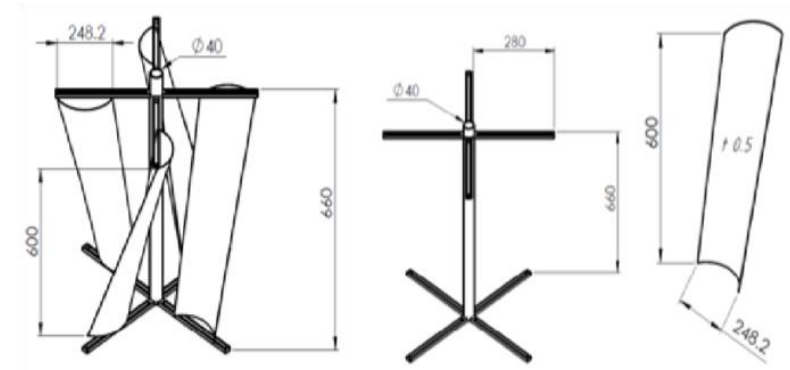

Gambar 3. Komponen Turbin Vortex Sudut Kemiringan Sudu $45^{\circ}$

Tabel 2 Data hasil perhitungan sudu pipa belah 3 dengan sudut kemiringan sudu $45^{\circ}$ 


\begin{tabular}{|c|c|c|c|c|c|c|c|c|c|c|}
\hline \multicolumn{7}{|c|}{ DATA HASIL PENGUJIAN } & \multicolumn{4}{|c|}{ DATA PERHITUNGAN } \\
\hline \multirow{2}{*}{ No } & \multirow{2}{*}{$\begin{array}{l}\text { Beban } \\
\text { (Watt) }\end{array}$} & \multirow{2}{*}{\begin{tabular}{|c|} 
Tegangan \\
(Nolt)
\end{tabular}} & \multirow{2}{*}{$\begin{array}{c}\text { Arus } \\
\text { (A) }\end{array}$} & \multicolumn{2}{|c|}{ Putaran (rpm) } & \multirow{2}{*}{$\begin{array}{c}\Delta \mathrm{x} \\
(\mathrm{cmHg})\end{array}$} & \multirow{2}{*}{$\begin{array}{c}Q \\
\left(m^{\wedge} 3 / s\right)\end{array}$} & \multirow{2}{*}{\begin{tabular}{|c|} 
Ph \\
(Watt) \\
\end{tabular}} & \multirow{2}{*}{$\begin{array}{c}\mathrm{Pg} \\
\text { (Watt) }\end{array}$} & \multirow{2}{*}{$\begin{array}{c}7 \\
(36) \\
\end{array}$} \\
\hline & & & & Turbin & Generato & & & & & \\
\hline 1 & 0 & 16 & 0 & 81.2 & 162.4 & 6 & 0.00794 & 38.7925 & 0 & 0 \\
\hline 2 & 5 & 13 & 0.32 & 78.6 & 157.2 & 6 & 0.00794 & 38.7925 & 4.16 & 10.72 \\
\hline 3 & 10 & 9.5 & 0.48 & 75.8 & 151.6 & 6 & 0.00794 & 38.7925 & 4.56 & 11.75 \\
\hline 4 & 15 & 7.8 & 0.49 & 73.2 & 146.4 & 6 & 0.00794 & 38.7925 & 3.822 & 9.852 \\
\hline 5 & 20 & 6.8 & 0.5 & 70.8 & 141.6 & 6 & 0.00794 & 38.7925 & 3.4 & 8.764 \\
\hline 6 & 25 & 5.6 & 0.59 & 69.4 & 138.8 & 6 & 0.00794 & 38.7925 & 3.304 & 8.517 \\
\hline 7 & 30 & 4.4 & 0.65 & 68 & 136 & 6 & 0.00794 & 38.7925 & 2.86 & 7.372 \\
\hline 8 & 35 & 4 & 0.69 & 65.8 & 131.6 & 6 & 0.00794 & 38.7925 & 2.76 & 7.114 \\
\hline 9 & 40 & 3.2 & 0.73 & 64.9 & 129.8 & 6 & 0.00794 & 38.7925 & 2.336 & 6.021 \\
\hline 10 & 45 & 2.8 & 0.77 & 63.3 & 126.6 & 6 & 0.00794 & 38.7925 & 2.156 & 5.557 \\
\hline 11 & 50 & 2.2 & 0.78 & 63 & 126 & 6 & 0.00794 & 38.7925 & 1.716 & 4.423 \\
\hline 12 & 55 & 2.2 & 0.79 & 62.7 & 125.4 & 6 & 0.00794 & 38.7925 & 1.738 & 4.480. \\
\hline 13 & 60 & 2 & 0.8 & 62.2 & 124.4 & 6 & 0.00794 & 38.7925 & 1.6 & 4.124 \\
\hline 14 & 65 & 1.8 & 0.82 & 61.8 & 123.6 & 6 & 0.00794 & 38.7925 & 1.476 & 3.804 \\
\hline 15 & 70 & 1.6 & 0.83 & 61.3 & 122.6 & 6 & 0.00794 & 38.7925 & 1.328 & \begin{tabular}{|l|}
3.423 \\
\end{tabular} \\
\hline 16 & 75 & 1.8 & 0.86 & 60.6 & 121.2 & 6 & 0.00794 & 38.7925 & 1.548 & 3.990 \\
\hline 17 & 80 & 1.8 & 0.84 & 60.4 & 120.8 & 6 & 0.00794 & 38.7925 & 1.512 & 3.897 \\
\hline 18 & 85 & 1.8 & 0.85 & 61.8 & 123.6 & 6 & 0.00794 & 38.7925 & 1.53 & 3.944 \\
\hline 19 & 90 & 1.8 & 0.82 & 60.9 & 121.8 & 6 & 0.00794 & 38.7925 & 1.476 & 3.804 \\
\hline 20 & 95 & 1.8 & 0.84 & 60.5 & 121 & 6 & 0.00794 & 38.7925 & 1.512 & 3.897 \\
\hline 21 & 100 & 1.8 & 0.83 & 61 & 122 & 6 & 0.00794 & 38.7925 & 1.494 & 3.851 \\
\hline 22 & 110 & 1.3 & 0.88 & 60.4 & 120.8 & 6 & 0.00794 & 38.7925 & 1.144 & 2.949 \\
\hline 23 & 120 & 1.2 & 0.88 & 61.5 & 123 & 6 & 0.00794 & 38.7925 & 1.056 & 2.722 \\
\hline 24 & 130 & 1.2 & 0.9 & 59.8 & 119.6 & 6 & 0.00794 & 38.7925 & 1.08 & 2.784 \\
\hline 25 & 140 & 1.2 & 0.91 & 59.7 & 119.4 & 6 & 0.00794 & 38.7925 & 1.092 & 2.814 \\
\hline 26 & 150 & 1.1 & 0.88 & 60.1 & 120.2 & 6 & 0.00794 & 38.7925 & 0.968 & 2.495 \\
\hline 27 & 160 & 1 & 0.89 & 59.4 & 118.8 & 6 & 0.00794 & 38.7925 & 0.89 & 2.294 \\
\hline
\end{tabular}

menggunakan data sudu pipa belah 3 dengan sudut sudu $0^{\circ}$ pada data nomor 2 dan diperoleh data sebagai berikut :

$$
\begin{aligned}
\mathrm{V} & =12 \text { volt } \mathrm{I} \\
& =0,19
\end{aligned}
$$

ampere $\mathrm{n}_{\mathrm{t}} \quad=74,2$

$\operatorname{rpm~n}_{\mathrm{g}} \quad=$

$148,4 \mathrm{rpm}$

$$
\mathrm{H}=0,50 \mathrm{~m}
$$$$
\Delta \mathrm{x}=0,06 \mathrm{~m}
$$

\section{Perhitungan}

debitUntuk

menghitung debit digunakan orifice dengan spesifikasi sebagai berikut:

$$
\begin{aligned}
\mathrm{D}_{\text {pipa }} & =84 \mathrm{~mm}=0,084 \mathrm{~m} \mathrm{~d}_{\text {orifice }} \\
= & 60 \mathrm{~mm}=0,060 \mathrm{~m} \\
A_{1} & =\frac{1}{4} \pi D^{2} \\
A_{1} & =\frac{1}{4} \cdot 3,14 \cdot(0,084)^{2} \\
A_{1} & =0,00553896 \mathrm{~m}^{2} \\
A_{2} & =\frac{1}{4} \pi d^{2} \\
A_{2} & =\frac{1}{4} \cdot 3,14 \cdot(0,060)^{2}
\end{aligned}
$$

$$
\begin{aligned}
& A_{2}=0,002826 \mathrm{~m}^{2} \\
& \text { Diketahui nilai } \mathrm{Cd}=0,628 \\
& \mathrm{Q}=\mathrm{Cd} \cdot \frac{A_{2} \cdot A_{1}}{\sqrt{{A_{1}^{2}-\mathrm{A}_{2}^{2}}^{2}}} \cdot \sqrt{2 \cdot g \cdot \Delta x\left(\frac{S_{\text {airraksa }}}{S_{\text {air }}}-1\right)} \\
& \mathrm{Q}=\operatorname{Cd} \cdot \frac{A_{2} \cdot A_{1}}{\sqrt{A_{1}^{2}-\mathrm{A}_{2}^{2}}} \cdot \sqrt{2 \cdot g \cdot \Delta x\left(\frac{S_{\text {airraksa }}}{S_{\text {air }}}-1\right)} \\
& \text { Q } \\
& =0,628 . \frac{\frac{3,14}{4}\left(0,060^{2}\right) \times \frac{3,14}{4}\left(0,084^{2}\right)}{\sqrt{\left[\left(\frac{3,14}{4}\left(0,084^{2}\right)\right)^{2}-\left(\frac{3,14}{4}\left(0,060^{2}\right)^{2}\right]\right.}} . \\
& \sqrt{2.9,806 \cdot \Delta x\left(\frac{13,6}{1}-1\right)} \\
& \mathrm{Q}=0,628 . \mathrm{Q}=0,628 \\
& \times 0,003285 \times \\
& 3,8495 \\
& \mathrm{Q}=7,943375 \times 10^{-3} \mathrm{~m}^{3} / \mathrm{s}
\end{aligned}
$$

2. Perhitungan Daya Hidrolik $\left(\mathrm{P}_{\mathrm{h}}\right)$ Dimana :

$\rho=995,9 \mathrm{Kg} / \mathrm{m}^{3} \mathrm{~g}=9,806 \mathrm{~m} / \mathrm{s}^{2}$

$\mathrm{Q}=7,943375 \times 10^{-3} \mathrm{~m}^{3} / \mathrm{s}$

$\mathrm{H}=0,50 \mathrm{~m}$

$\mathrm{P}_{\mathrm{h}} \quad=\rho \cdot \mathrm{g} \cdot \mathrm{Q} \cdot \mathrm{H}$

$\mathrm{P}_{\mathrm{h}} \quad=995,9 \cdot 9,806 \cdot 7,943375 \times$

$10^{-3 \cdot 0,5}$

$\mathrm{P}_{\mathrm{h}} \quad=38,79246 \mathrm{Watt}$

3. Perhitungan Daya Generator $\left(\mathrm{P}_{\mathrm{g}}\right)$ Dimana :

$\mathrm{V}=12$ Volt

$\mathrm{I}=0,19 \mathrm{~A}$

$\mathrm{P}_{\mathrm{g}}=\mathrm{V} . \mathrm{I}$

$\mathrm{P}_{\mathrm{g}}=12 \times 0,19$

$\mathrm{P}_{\mathrm{g}}=2,28 \mathrm{Watt}$

4. Perhitungan Efisiensi Sistem $\left(\eta_{\mathrm{s}}\right)$

$$
\begin{gathered}
\eta_{\mathrm{s}}=\frac{\mathrm{Pg}_{\mathrm{g}}}{P_{h}} \times 100 \% \\
\eta_{\mathrm{s}}=\frac{2,28}{38,79246} \times 100 \% \\
\eta_{\mathrm{s}}=5,87743 \%
\end{gathered}
$$


Untuk contoh perhitungan 2 menggunakan data sudu pipa belah 3 dengan sudut kemiringan sudu $45^{\circ}$ pada data nomor 2 dan diperoleh data sebagai berikut:

$$
\begin{aligned}
\mathrm{V} & =13 \text { volt } \mathrm{I} \\
& =
\end{aligned}
$$

0,32ampere $\mathrm{n}_{\mathrm{t}}=$

$78,6 \mathrm{rpm} \mathrm{n}_{\mathrm{g}} \quad=$ $157,2 \mathrm{rpm}$

$$
\begin{array}{ll}
\mathrm{H} & =0,50 \mathrm{~m} \\
\Delta \mathrm{x} & =0,06 \mathrm{~m}
\end{array}
$$

1.Perhitungan debitUntuk menghitung debit digunakan orifice dengan spesifikasi sebagai berikut:

$$
\begin{aligned}
& \mathrm{D}_{\text {pipa }}=84 \mathrm{~mm}=0,084 \mathrm{~m} \mathrm{~d}_{\text {orifice }} \\
& =60 \mathrm{~mm}=0,060 \mathrm{~m} \\
& A_{1}=\frac{1}{4} \pi D^{2} \\
& A_{1}=\frac{1}{4} \cdot 3,14 \cdot(0,084)^{2} \\
& A_{1}=0,00553896 \mathrm{~m}^{2} \\
& A_{2}=\frac{1}{4} \pi d^{2} \\
& A_{2}=\frac{1}{4} \cdot 3,14 \cdot(0,060)^{2} \\
& A_{2}=0,002826 \mathrm{~m}^{2}
\end{aligned}
$$

$$
\begin{aligned}
& \mathrm{Q}=\operatorname{Cd} \cdot \frac{A_{2} \cdot A_{1}}{\sqrt{A_{1}^{2}-\mathrm{A}_{2}^{2}}} \cdot \sqrt{2 \cdot g \cdot \Delta x\left(\frac{S_{\text {airraksa }}}{S_{\text {air }}}-1\right)} \\
& \mathrm{Q}=\operatorname{Cd} \cdot \frac{A_{2} \cdot A_{1}}{\sqrt{{A_{1}^{2}-\mathrm{A}_{2}^{2}}^{2}}} \cdot \sqrt{2 \cdot g \cdot \Delta x\left(\frac{S_{\text {airraksa }}}{S_{\text {air }}}-1\right)}
\end{aligned}
$$

Q

$$
\begin{gathered}
=0,628 . \frac{\frac{3,14}{4}\left(0,060^{2}\right) \times \frac{3,14}{4}\left(0,084^{2}\right)}{\sqrt{\left[\left(\frac{3,14}{4}\left(0,084^{2}\right)\right)^{2}-\left(\frac{3,14}{4}\left(0,060^{2}\right)^{2}\right]\right.}} . \\
\sqrt{2.9,806 \cdot \Delta x\left(\frac{13,6}{1}-1\right)} \\
Q=0,628 . \times 0,003285 \times 3,8495 \\
Q=7,943375 \times 10^{-3} \mathrm{~m}^{3} / \mathrm{s}
\end{gathered}
$$

2. Perhitungan Daya Hidrolik $\left(\mathrm{P}_{\mathrm{h}}\right)$

$$
\text { Dimana }: \rho=995,9 \mathrm{Kg} / \mathrm{m}^{3}
$$

$\mathrm{g}=9,806 \mathrm{~m} / \mathrm{s}^{2}$

$\mathrm{Q}=7,943375 \times 10^{-3} \mathrm{~m}^{3} / \mathrm{s}$

$\mathrm{H}=0,50 \mathrm{~m}$

$$
\begin{array}{ll}
\mathrm{P}_{\mathrm{h}} & =\rho \cdot \mathrm{g} \cdot \mathrm{Q} \cdot \mathrm{H} \\
\mathrm{P}_{\mathrm{h}} & =995,9 \cdot 9,806 \cdot 7,943375 \times \\
& 10^{-3} \cdot 0,5 \\
\mathrm{P}_{\mathrm{h}} & =38,79246 \mathrm{Watt}
\end{array}
$$

3. Perhitungan Daya Generator $\left(\mathrm{P}_{\mathrm{g}}\right) \mathrm{Di}$ mana :

$$
\begin{aligned}
& \mathrm{V}=13 \text { Volt } \\
& \mathrm{I}=0,19 \mathrm{~A} \\
& \mathrm{P}_{\mathrm{g}}=\mathrm{V} . \mathrm{I} \\
& \mathrm{P}_{\mathrm{g}}=13 \times 0,32 \\
& \mathrm{P}_{\mathrm{g}}=4,16 \text { Watt }
\end{aligned}
$$

4. Perhitungan Efisiensi Sistem $\left(\eta_{\mathrm{s}}\right)$

$$
\begin{gathered}
\eta_{\mathrm{s}}=\frac{\mathrm{Pg}_{\mathrm{g}}}{P_{h}} \times 100 \% \\
\eta_{\mathrm{s}}=\frac{4,16}{38,79246} \times 100 \% \\
\eta_{\mathrm{s}}=10,72373 \%
\end{gathered}
$$

Karakteristik Turbin Vortex dengan Sudu Pipa Belah Tiga dengan Sudut Sudu $0^{\circ}$ dan Sudut Kemiringan Sudu $45^{\circ}$. 


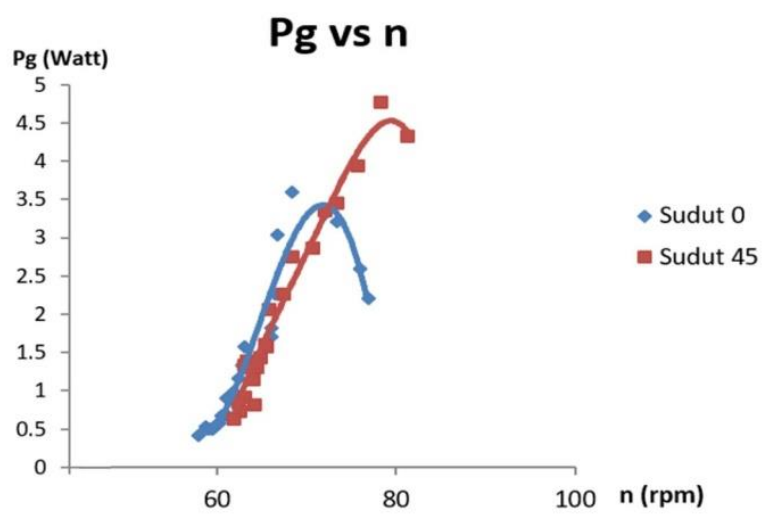

Gambar4. Karakteristik daya generator terhadap putaran turbin menggunakan sudut sudu $0^{\circ}$ dan sudut kemiringan sudu $45^{\circ}$.

Grafik diatas merupakan hasil pengujian Turbin Vortexdengan sudu pipa belah tiga dengan sudut sudu $0^{\circ}$ dan sudut kemiringan sudu $45^{\circ}$ pada debit yang sama dengan variabel putaran. Berdasarkan grafik diatas dapat diketahui bahwa,hubungan antara putaran turbin dengan daya generator menghasilkan suatu kurva parabola, dimana semakin besar putaran turbin maka semakin besar pula daya generator yang dihasilkan sampai mencapai puncak tertentu dan kemudian turun. Titik puncak tersebut merupakan titik optimum generator dapat menghasilkan daya terbesar. Titik pucak sudut sudu $0^{\circ}$ menghasilkan daya generator sebesar 3,528 watt pada putaran turbin $65,7 \mathrm{rpm}$. Titik puncak sudut kemiringan sudu $45^{\circ}$ menghasilkan daya generator sebesar 4,56 watt pada putaran 75,8 rpm.

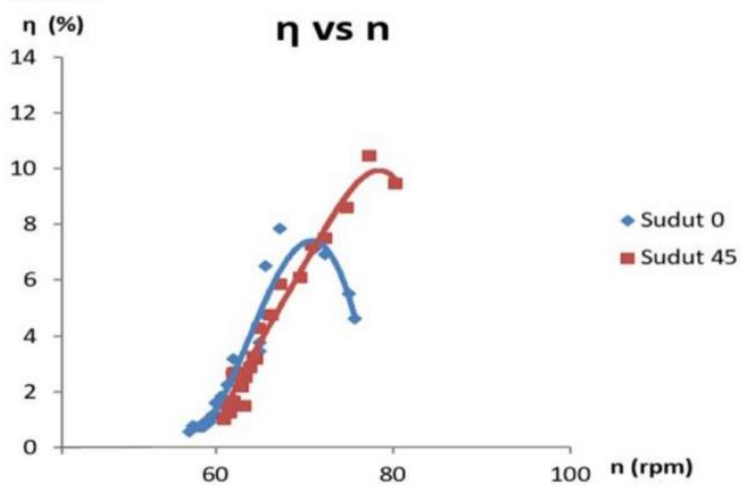

Gambar 5. Karakteristik efisiensi sistem terhadap putaran turbin menggunakan sudut sudu $0^{\circ}$ dan sudut kemiringan sudu $45^{\circ}$

Grafik diatas merupakan hasil pengujian Turbin Vortex dengan sudu pipa belah tiga dengan sudut sudu $0^{\circ}$ dan sudut kemiringan sudu $45^{\circ}$ pada debit yang sama dengan variabel putaran. Berdasarkan grafik diatas dapat diketahui bahwa hubungan antara putaran turbin dan efisiensi sistem menghasilkan suatu kurva parabola dimana semakin besar putaran turbin maka semakin besar pula efisiensi yang dihasilkan sampai mencapai puncak tertentu kemudian turun. Titik puncak tersebut merupakan titik optimum sistem dapat menghasilkan efisiensi terbesar. Titik pucak sudut sudu $0^{\circ}$ menghasilkan efisiensi sistem sebesar 9,094.

\section{KESIMPULAN}

Dari keseluruhan proses " Pembuatan Turbin Vortex dengan Sudu Pipa Belah Tiga dengan Sudut Kemiringan Sudu 45\%", dapat disimpulkan beberapa hal antara lain:

1. Spesifikasi turbin vortexberbentuk pipa belah tiga adalah sebagai berikut:

a. Diameter baskom pusaran air 700 $\mathrm{mm}$

b. Tinggi baskom pusaran air $800 \mathrm{~mm}$

c. Diameter lubang keluar air pada baskon pusaran air $97 \mathrm{~mm}$

d. Variasi sudu berbentuk pipa belah tiga dengan sudut $0^{\circ}$ dan sudu berbentuk pipa belah tiga dengan sudut kemiringan sudu $45^{\circ}$

e. Tebal sudu $0,5 \mathrm{~mm}$

f. Lebar sudu $248,2 \mathrm{~mm}$

g. Tinggi sudu $550 \mathrm{~mm}$ pada sudut sudu $0^{\circ}$

h. Tinggi sudu $600 \mathrm{~mm}$ pada sudut kemiringan sudu $45^{\circ}$ 
i. Bahan sudu terbuat dari stainless steel

2. Hasil uji kinerja turbin Vortex dengan bentuk sudu pipa belah tiga yang sudut kemiringan dibuat $45^{\circ}$ dan bentuk sudu pipa belah tiga yang sudut sudunya $0^{\circ}$, yaitu:

a. Berdasarkan grafik Karakteristik Daya Genertor terhadap Putaran Turbin didapatkan bahwa pada sudut sudu $0^{\circ}$ titik optimum generator menghasilkan daya terbesar 3,528 Watt pada putaran turbin $65,7 \mathrm{rpm}$. Sedangkan pada sudut kemiringan sudu $45^{\circ}$ titik optimum generator menghasilkan daya terbesar 4,56 Watt pada putaran turbin $75,8 \mathrm{rpm}$.

b. Berdasarkan grafik Karakteristik Efisiensi Sistem terhadap Putaran Turbin didapatkan bahwa pada putaran yang sama yaitu putaran 75 rpm sudut sudu $0^{\circ}$ menghasilkan efisiensi 4,8 \% sedangkan pada sudut kemiringan sudu $45^{\circ}$ menghasilkan efisiensi $9,6 \%$.

Berdasarkan hasil uji kinerja antara turbin vortexsudu pipa belah tiga sudut $0^{\circ}$ dengan sudut kemiringan sudu $45^{\circ}$, dapat disimpulkan bahwa sudu pipa belah tiga dengan sudut kemiringan sudu $45^{\circ}$ memiliki effisiensi yang lebih baik daripada sudut $0^{\circ}$.

\section{DAFTAR PUSTAKA}

Belajar Diesel. 2012.

https://belajardiesel.wordpress.com/2012/0 7/ (Maret 2018)

Departement of Chemical Engineering and Biotechnology. 2015.

http://www.ceb.cam.ac.uk/pages/ofm.facili ti es-and-equiment.html (Maret 2018)

Freeflowhydro.
http://freeflowhydro.co.uk/13/24/CINK/CI $\mathrm{N}$

K.html (April 2018) Heskon energi. 2010. http://www.heskonenerji.com.tr/eng/tekni kb ilgiler.html (Mei 2018) Kirmanto,djoko.2012. "Media informasi sumber daya air”. Jakarta Selatan : Kementrian Pekerjaan Umum.

L. Streeter Victor, dkk. 1991.Mekanika Fluida. Jakarta : Penerbit Erlangga M.M Dandekar dan K.N Sharma. 1991.

"Pembangkit listrik tenaga air". Jakarta : UI-Press

Marsudi, djiteng. 2006. "Pembangkitan energi listrik”. Jakarta : Erlangga

Mohanan, Anjali M. 2016. "Power generation with simulateous aeration using a gravity vortex turbine"

Internationational journal of Scientific \& engineering reseach. Volume 7. Nomor 2. India

Sihombing, Ray Poskom J dan Syahril Gultom. 2014. "Analisa efisiensi turbin vortex dengan casing berpenampang lingkaran pada sudu berdiameter $56 \mathrm{~cm}$ untuk variasi jarak dengan saluran keluaran". Sumatera Utara Tipe saluran masuk air (Inlet Area). 2012. https://yusufrandabunga.wordpress.com/ 